\title{
A Physical Internet-enabled Building Information Modelling System for Prefabricated Construction
}

\section{Ke CHEN ${ }^{1}$, Gangyan XU' ${ }^{2 a}$, Fan $\mathrm{XUE}^{3 \mathrm{~b}}$, Ray Y ZHONG ${ }^{4}$, Diandian Liu ${ }^{5}$, and Weisheng $\mathbf{L U}^{6}$}

1) PhD Candidate, Corresponding author, Department of Real Estate and Construction, The University of Hong Kong, Hong Kong, E-mail: leochen@connect.hku.hk, Telephone: +852 6486 7971;

2) $\mathrm{PhD}$ Candidate, Department of Industrial and Manufacturing Systems Engineering, The University of Hong Kong, Hong Kong. E-mail: gangyan@hku.hk;

3) Post-doctoral Fellow, Department of Building and Real Estate, The Hong Kong Polytechnic University, Hong Kong, E-mail: fan.xue@polyu.edu.hk;

4) Lecturer, Department of Mechanical Engineering, University of Auckland, Auckland, New Zealand, E-mail: r.zhong@auckland.ac.nz;

5) MPhil Candidate, Department of Real Estate and Construction, The University of Hong Kong, Hong Kong. E-mail: liudd@connect.hku.hk;

6) Associate Professor, Department of Real Estate and Construction, The University of Hong Kong, Hong Kong, E-mail: wilsonlu@hku.hk;

\footnotetext{
${ }^{a}$ New affiliation: Research Fellow, School of Mechanical and Aerospace Engineering, Nanyang Technological University, Singapore. E-mail: gagexgy@gmail.com;

b New affiliation: Research Assistant Professor, Department of Real Estate and Construction, The University of Hong Kong, Hong Kong, E-mail: xuef@hku.hk;
} 


\title{
A Physical Internet-enabled Building Information Modelling System for Prefabricated Construction
}

\begin{abstract}
Prefabricated construction is believed to be energy conserving though opportunities for achieving higher energy efficiency have yet to be fully harnessed. From investigation of a prefabricated construction project in Hong Kong, two main problems have been revealed relating to energy consumption, including: i) inefficient management of resources such as labours and machines, and ii) inefficient production, transportation, and on-site assembly of prefabricated components. These problems are primarily caused by lagged information communication and human errors. This paper seeks to offer a solution by developing a Physical Internet-enabled Building Information Modelling System (PI-BIMS) that integrates Auto-ID technologies, BIM, and cloud computing. The PI-BIMS enables real-time collection, communication, and visualization of information across the processes of production, transportation, and on-site assembly. Practical issues of the system implementation are provided through a pilot prototype. It is found that the PIBIMS helps enhance the resource allocation efficiency and decrease human errors. Thus, an alternative opportunity to improve energy efficiency in prefabricated construction has become possible.
\end{abstract}

Keywords: prefabricated construction; energy efficiency; Physical Internet; Building Information Modelling (BIM); cloud technologies

\section{Introduction}

Construction is arguably one of the most energy-intensive industries around the world. Each year, the building sector consumes roughly $40 \%$ of the energy used globally (Dixit et al. 2010). Subject to rising energy costs and growing environmental concerns, energy-efficient ways of delivering construction projects is necessary. Compared with conventional methods featured by in-situ casting and wet trades, prefabricated construction emphasizes mass production of building components in off-site factories and on-site assemblies (Gibb 1999). It has been recognized as 
consuming less energy than traditional methods (Yee 2001; Lu and Yuan 2013). For example, Hong et al. (2016) found that up to $14 \%$ of the total energy consumption could be saved by using prefabricated components over using an equivalent amount of cast-in-place ones.

Despite a modest improvement in energy conservation, some challenges in prefabricated construction are existing. Firstly, a substantial amount of energy is still spent on the offsite production of components (Reddy and Jagadish 2003). Advancing the energy efficiency in the manufacturing process is demanded. Secondly, as prefabrication factories are usually located far away from construction sites, the transportation of prefabricated components consumes a considerable amount of energy (Zhong et al. 2013a). A more accurate logistics approach thus is needed. Thirdly, when carrying out the on-site assembly, the energy used is dependent not only on physical properties of prefabricated components, but also on the assembly sequences (Neelamkavil 2009). More effective ways of handling components are required to avoid wasting energy.

In the contemporary prefabricated construction, however, there is a lack of real-time project information that can be shared among various stakeholders. As a result, it is difficult for the manufacturers, contractors, and logistics companies to efficiently make plans and manage resources such as labours and machines. They thus make decisions depending on past experiences, which lead to energy dissipations (Heydarian and Golparvar-Fard 2011). Moreover, it is difficult to eliminate human errors when a job is conducted largely by manual efforts. A substantial amount of energy, therefore, would be consumed wastefully for addressing consequences of human errors. 
Towards higher energy efficiency in prefabricated construction, it is crucial to improve information collection and communication across processes of production, transportation, and on-site assembly and to reduce human errors. The advent of Building Information Modelling (BIM) and Physical Internet (PI) offers promising solutions. BIM is a digital representation of physical and functional characteristics of a project, which serves as a shared information resource for project management (NIBS 2015). PI denotes an open global supply chain system (Montreuil 2011), in which various objects are traced in a real-time manner (Qiu et al. 2015; Zhang et al. 2015). This research introduces a PI-enabled BIM System (PI-BIMS) that collects and communicates real-time project information for ultimately enhancing energy efficiency in prefabricated construction by piloting a system prototype in a real-life case in Hong Kong.

Remaining contents start with a literature review in Section 2, followed by an introduction of the PI-BIMS architecture in Section 3. The case study project is introduced in Section 4, where existing energy consumption issues are revealed. Section 5 describes how the prototype is devised, and Section 6 discusses how the system enhances the working practices towards higher energy efficiency from a reallife case study project. The system validation is given in Section 7. Section 8 concludes this paper.

\section{Literature review}

Recently, an intensive attention has been placed on energy conservation with a steep increase in studies projected to enhance energy efficiency in the Architecture, Engineering, Construction, and Operations (AECO) industry. Energy consumed in the AECO industry can be categorized into two types: (1) the operating energy (OE) used 
for maintaining the inside environment during the service life of a building; and (2) the embodied energy (EE) that goes into processes of production, transportation, construction, and final demolition (Crowther 1999; Treloar, Love, and Holt 2001).

In the relevant literature, focuses have been placed on the OE (e.g., Bazjanac 2004; Laine, Karola, and Oy 2007; Bynum, Issa, and Olbina 2012). It is because the service life usually accounts for a long building life-cycle. Scholars also argued that the design stage could play an important role in saving OE (Eichholtz, Kok, and Quigley 2010). Supported by Azhar et al. (2011), a sustainable design on average could save $20 \%$ of total life-cycle construction costs. In accordance with this viewpoint, Bazjanac (2004) proposed that, by offering more accurate energy simulations, the interoperable software could help select a design with the best energy performance among possible designs. Similarly, Laine, Karola, and Oy (2007) simulated the energy performance when designing buildings by utilizing BIM as a data source. Confining to the design stage, they inspiringly argued that it was crucial to verify energy performances at different project stages, which can only be achieved by BIM-enabled interoperability. Following this idea, many researchers adopted BIM at the design stage to simulate the OE for enhancing energy efficiency in a project life-cycle (e.g., Krygiel and Nies 2008; Stadel et al. 2011).

Thanks to previous research achievements, the potential for curbing the $\mathrm{OE}$ is able to be attained. There thus emerges a call for shifting emphases to conserving the EE of buildings. The concept of supply chain management (SCM) was adopted for enhancing energy efficiency in construction projects, particularly for prefabricated ones (Neelamkavil 2009). Just-in-Time (JIT) philosophy was another managerial concept aiming at smoothening the production process by efficient handling of materials. Pheng and Chuan (2001) studied applications of JIT to prefabricated 
construction. Through JIT, waste generations could be minimized and energy efficiency could be improved in prefabricated construction (Jeong et al. 2016).

Researchers also have striven efforts to conserve energy regarding individual processes of prefabricated construction projects. For instance, Hu (2005) developed an automatic determination method for arranging assembly sequences. Benjaoran and Dawood (2006) developed an innovative planning system for automating the production planning of prefabricated components. Babič, Podbreznik, and Rebolj (2010), Li et al. (2011), Irizarry, Karan, and Jalaei (2013) and many other researchers also proposed approaches to optimizing operations of manufacturing and transportation processes. In these studies, advanced technologies such as Auto-ID technologies and BIM were often adopted given their capabilities of real-time information collection and processing (Zhong et al. 2017).

The literature of conserving energy in prefabricated construction is insightful. However, building components are either tightly tracked within a single project process but loosely connected to rest processes, or being managed by following JIT or SCM but without details of how to attain such managerial concepts. This paper thus is significant as it proposes a PI-BIMS that offers real-time component information for resource allocation and reducing human errors from the prefabrication factory to the construction site. Moreover, details of how to implement the PI-BIMS for energy efficiency are unfolded by piloting a system prototype in a real-life prefabricated construction project.

\section{Physical Internet-enabled BIM System (PI-BIMS)}

\subsection{System architecture}

In the proposed PI-BIMS, PI is enabled by Auto-ID technologies following the 
existing research in the manufacturing industry (Montreuil, Meller, and Ballot 2013; Gubbi et al. 2013; Zhong et al. 2013b), and is tailored to fit the prefabricated construction context. In addition, a cloud BIM is developed by integrating BIM and cloud computing technologies that allow processing and visualizing the real-time information offered by PI (Chuang, Lee, and Wu 2010). The architecture of the PIBIMS consists of three layers, including, from bottom to top, the data collection layer, the intermediate layer, and the energy efficiency support layer (see Figure 1).

[Figure 1 near hear]

(1) The data collection layer contains smart construction objects (SCOs) and Auto-ID devices for real-time data collection. The SCOs refer to typical construction objects, such as prefabricated components, trucks, and trailers, which are made smart by equipping with Auto-ID tags (Niu et al. 2015). Relevant information about individual SCOs, such as the real-time status, can be quickly traced and collected by Auto-ID readers that are held by workers or fixed at value-adding points (e.g., the entrance gate on-site). The collected information is then transmitted to upper layer via communication networks.

(2) The intermediate layer is comprised of smart gateways which act as a bridge between the frontline data collection layer and the energy efficiency support layer. A smart gateway consists of a hardware hub and the software working in a "plug and play" fashion. It has three main functions. Firstly, it configures and manages all SCOs in the project. Secondly, it controls the data transfer between Auto-ID devices and SCOs. Thirdly, it communicates the collected information in a standardized format. 
(3) The energy efficiency support layer refers to three cloud-based platforms that support the production, transportation, and on-site assembly of prefabricated components respectively. The primary functions of this layer are to process and visualize the real-time information in BIM environment, as well as to timely record the information in databases and enable seamless communication throughout the project life-cycle.

\subsection{Innovative modules for end-users}

PI-BIMS contains three primary modules: Traceability, Visibility, and Information Exchange. These modules are essential to solve energy consumption problems caused by inefficient resource management and human errors.

(1) The traceability module, mainly based on the Auto-ID technologies, is designed to trace the information of individual prefabricated components and associated tasks of production, transportation, and on-site assembly. The traced information, including production stage, location, and assembly stage of a prefabricated component, is important for resource management towards higher energy efficiency.

(2) The visibility module is designed to integrate, visualize, and explore the components' statues and associated tasks in a graphical interface. This module not only offers detailed information of individual components, but reveals a complete picture of the entire project with new insights to managers. The visibility module thus is essential for saving energy through helping managers making more accurate production plans, transportation schedules, and on-site assembly tasks. It is also helpful for workers to check 
their finished works, and for managers to supervise the tasks conducted by workers in a real-time manner.

(3) The information exchange module is devised to enable information in one cloud platform to be seamlessly shared. As a prefabricated construction project often engages more stakeholders compared to a conventional project, efficient information communication becomes even more crucial for addressing any energy consumption issue. This module maintains the information consistency throughout the project processes and ensures the right information is delivered to the right person at the right time (Chen et al. 2015).

\section{Energy consumption issues in prefabricated construction}

\subsection{Case study project}

The case study project comes from a real-life a prefabricated construction project in Hong Kong. It has five building blocks, one of which has 37 floors that need 7,103 prefabricated components of 13 different types (Zhong et al. 2017). These components are supplied by a prefabrication manufacturer (Company A) located in Boluo County of Mainland China, about 130 miles away from the construction site. The logistics services are provided by Company B that also offers transhipment warehouse for temporary component storages. The construction work is undertaken by Company C, which is a leading contractor in Hong Kong.

\subsection{Existing energy consumption issues}

A two months' pre-pilot research through weekly on-site observations and face-toface interviews have been conducted. A total of eight site visits were completed. Thus 
the entire processes of the prefabrication production, transportation, and on-site assembly were recorded. Particularly, energy consumption issues were identified as follows.

\subsubsection{The production process}

Once receiving a production order from Company C, a manager from Company A established a production plan. According to the plan, workers produced prefabricated components following seven steps, viz., preparation, moulding, reinforcing, concreting, quality check, curing, and demoulding. On the surface of each produced component, workers manually printed a sequential number and fastened a plastic label to it specifying the project name and component code. Then, the component would be temporarily stocked at storage yards. Workers would also record the production information (e.g., finishing time, component code, etc.) on papers and hand over the paper documents to a worker who was responsible for documentation management. These onwards, the produced prefabricated components were stored in the finished product warehouse waiting for delivery.

During this process, a major energy consumption issue was that the production plan cannot adjust order changes in a timely manner. In the pre-pilot period, Company C averagely changed orders two times per week due to various reasons such as design and engineering changes. When acknowledging such changes, it was often too late for Company A to make proper reactions. Consequently, unexpected inventory occurred, leading to a waste of energy on sorting, managing, and damage-preventing of these components. More seriously, some produced components even became unsuitable for the case study project due to changes in specifications, which resulted in an extra usage of energy for discarding wrong productions and reproducing right components. 


\subsubsection{The transportation process}

The transportation process started with Company A receiving the delivery order from Company C. A manager from Company A made the transportation plan and notified Company B about the upcoming transportation tasks in one-day advance. Meanwhile, the manager informed workers about the prefabricated components to be delivered. Workers in Company A found the required components in the finished product warehouse according to the sequential number printed on the component surface, and loaded them on trailers. After confirming the loading condition, workers manually recorded the information of loaded components in paper-based reports.

The manager from Company B reviewed the transportation tasks and assigned the driver and the truck for each task. Drivers from Company B picked the trailer at the warehouse of Company $\mathrm{A}$, and then transported the components together with paper-based delivery dockets to the construction site. After customs clearance, the components were either directly sent to the construction site or temporarily stored at a transhipment warehouse. On arriving at the construction site, the transported components were unloaded and stocked on-site.

As the trailer to be transported was manually located, it was possible that the truck was connected to a wrong trailer. Actually, during the pre-pilot period, five times of incorrect transportation happened. The incorrectly transported components had to be temporarily stored at the transhipment warehouse, and another delivery with right components must be immediately arranged. An extra amount of energy thus was spent on unnecessary transportations. In addition, since the manager from Company C lacked the delivery status, resources (e.g., labours, machines) could not be efficiently allocated for incoming component batches. Energy hence was wasted as machines 
usually had a relatively long idle time before receiving the components for on-site assembly.

\subsubsection{The on-site assembly process}

For each round of on-site assembly, the manager from Company $\mathrm{C}$ informed three workers to finish the task. The first worker manually searched from the on-site storage for the required component according to the printed sequential number. The second worker operated the tower crane to lift the component to the target position. The third worker was responsible for directing the tower crane to ensure that the component was fixed in the right position. After the installation, that third worker made paper-based records and reported the completion of the task to the manager.

During this process, three energy consumption issues were recognized. Firstly, workers had to spend considerable time on manually searching the required components, during which time, the tower crane was idle. Secondly, manual inspection conducted for checking whether the right components were found. Wrong installations might happen causing wasteful consumption of energy for knocking down the incorrectly installed components and conducting re-installation. Thirdly, the paper-based reports were not sufficient to timely track the construction progress. It thus was difficult for managers to arrange construction resources in an efficient fashion.

\section{The PI-BIMS prototype}

For solving the above-identified issues in the case study project, a PI-BIMS prototype has been developed. Specifically, two kinds of RFID tags including ultra-high frequency (UHF) and high frequency (HF) tags have been used. The UHF tags were attached to the prefabricated components to ensure the radio wave can penetrate the 
concrete cover. The HF tags were attached to the trucks and trailers since they have reliable performance when mounted on metal surfaces. Other main hardware of the prototype includes TSL1128 Bluetooth ${ }^{\circledR}$ UHF RFID Reader, the smartphone equipped with the Global Positioning System (GPS) sensor and Near Field Communication (NFC).

Three platforms, viz., the prefabrication production platform (PPP), the prefabrication transportation platform (PTP), and the on-site assembly platform (OAP), have been designed for the three companies respectively. The database of OAP was designed for storing the original design information of each prefabricated component and on-site assembly information. For PPP and PTP, their databases were mainly for storing the production information and transportation information respectively. Each of the three platforms contained a smartphone App and a web service. Smartphone Apps were developed for workers to check their daily tasks. These Apps made the smartphones as gateways that managed the tag-attached prefabricated components, trucks, and trailers, and sent the real-time information to databases. Web services were developed for managers of the three companies to arrange tasks and allocate resources based on the shared real-time information.

The prototype system has been tested at three levels, including module testing, integration testing, and online testing. Module testing was conducted by using white box testing strategy to ensure the compatibility of individual function modules. Integration testing was to verify the integrity of the entire functional processes, and the connection among the developed platforms. Online testing used experimental scenarios to evaluate the compliance of the system with requirements of supporting different project processes. After testing, selected workers and managers of the three companies were trained to use the prototype. 


\section{Enhanced energy efficiency by the PI-BIMS}

The duration of piloting the PI-BIMS prototype in the case study project is nine months. The overall workflow after applying the prototype is presented in Figure 2. How the new workflow brought about higher energy efficiency, enabled by the PIBIMS, will be introduced along with processes of production, transportation and onsite assembly.

[Figure 2 near here]

\subsection{Energy efficient prefabrication production}

[Figure 3 near here]

The re-engineered workflow of prefabrication production is exhibited in Figure 3. The connection between PPP and OAP allows the production order from Company C being communicated to Company $\mathrm{A}$ in a paperless and efficient manner. At the beginning of each production round, the manager from Company $\mathrm{C}$ selects digital prefabricated components in the web service of OAP and sets the date when these components should be ready. Then, OAP automatically generates an order list containing the complete information of required components, including type, floor, flat, component code, design drawing, quantity, date, etc. The generated order is automatically sent to PPP. When an order needs to be changed, any approved changes are updated in different platforms simultaneously.

Based on the received production order, the manager in Company A can establish the production plan in PPP and make timely adjustments to avoid wrong productions. Workers can receive the daily production plan via the smartphone App of PPP, including the type and quantity of components to be produced on a certain day. They can also view the design drawings and thus make more efficient preparations such as preparing the correct reinforcement cage and mould. 
When producing a prefabricated component, a UHF tag is attached to the reinforcement cage of that component. After that, a worker selects the produced component in the smartphone App and scans the tag by a RFID reader. The information will be transmitted to the worker's smartphone via Bluetooth. This links the prefabricated component with the RFID tag and recorded the status of that component to "Produced" automatically. The smartphone App then uploads the status and other information about the produced component to the database. In this way, the production information is timely recorded and revealed in PPP where the manager is able to review the real-time project progresses.

\subsection{Energy efficient prefabrication transportation}

[Figure 4 near here]

The rationalized workflow of prefabrication transportation is shown in Figure 4. The synchronization of PTP, PPP, and OAP is useful for enhancing the energy efficiency of the transportation process. In this process, a delivery order is firstly made by the manager from Company $\mathrm{C}$ in the web service of OAP. The delivery order is transferred to the web service of PPP for the manager from Company A to make loading and transportation plans.

Workers in Company A receive loading tasks in the smartphone App. Before loading a component on the trailer, workers use a RFID reader to scan the tag deployed on the prefabricated component to check whether it is the right one. Once confirmed, the component will be loaded on the trailer. Workers then select the component in the smartphone App of PPP, and scan the HF tag deployed on the trailer by the NFC. This operation binds the loaded component with the trailer. At the meantime, the loading time of the prefabricated component is recorded and transmitted to the database of PPP automatically. 
The manager from Company B can view the latest transportation plan via the web service of PTP. All transportation tasks are evaluated to identify their priorities. Then, the manager assigns a driver and a truck to each task. The assigned task will be stored in the database of PTP. Together with the binding information of components and trailer from PPP, the driver, truck, trailer, and components for each transportation task are combined.

Drivers from Company B use the smartphone App of PTP to check the transportation task. Then, they drive the assigned truck to the storage yard in Company A to pick the trailer with the components. They will use the smartphone with NFC function to scan the HF tags deployed on both the truck and trailer to confirm their correctness. If a wrong trailer is picked, the smartphone App will give an alarm. When passing the cross-border customs and approaching to the construction site, drivers can update status via App of PTP so that the status is shared among different stakeholders.

\subsection{Energy efficient on-site assembly}

[Figure 5 near here]

The improved workflow of the on-site assembly is shown in Figure 5. The connection between the three platforms enables on-site activities heading towards higher energy efficiency. Foremost, with the status of prefabricated components from PPP and PTP, the manager from Company $\mathrm{C}$ allocates resources for carrying out the construction work, such as arranging labour forces and dispatching machines, more efficiently and thereby avoid non-value-adding activities.

For the assembly execution, OAP ensures that the right components for an installation task are located to avoid wrong on-site assemblies. Workers of Company $\mathrm{C}$ receive a list of components to be assembled in the smartphone App of OAP. When 
workers find a required component in the site storage area, they firstly scan its RFID tag. The information of that component (e.g., 3D drawings) is then shown in the App. Therefore, workers can check whether the right component is ready for installation and acknowledge the exact position where the component is to be installed. With the confirmation made by workers, the manager can arrange the tower crane and other resources more accurately to avoid the idle time of both labours and machines.

In addition, OAP helps workers to confirm that the prefabricated component is installed at the right position. This is done by scanning the RFID tag integrating a smartphone GPS sensor. The workers will be noticed by the difference between the collected location and the as-designed location from the BIM model. In case the result is not satisfactory, i.e., a component is placed at a wrong place, the component can be removed before it is connected with the in-situ concreting structure. By using this function, assembly and installation accuracy is improved, and thereby wasteful energy consumption is avoided.

Based on the completed on-site assembly recorded in the database of OAP and a BIM model with the analytical figures, the manager can review the current site storage and the actual construction progress. Such real-time information helps the manager to make plans more efficiently.

\section{System validation}

Both qualitative and quantitative analyses have been carried out to validate the PIBIMS. The qualitative analysis was based on 18 times of semi-structured interviews with seven workers and one manager from Company A, two drivers and one manager from Company B, and five workers and two managers from Company C. The majority of interviewees agreed that the PI-BIMS is useful for improving energy 
efficiency in the case study project. The quantitative analysis was done through comparing performances (e.g. the operation time and the accuracy of on-site assembly) before and after using the PI-BIMS (see Table 1). During the pilot period of 9 months, the implementation of the PI-BIMS prototype consumed $12.419 \mathrm{kWh}$ of electricity in total, which is significantly lower than the energy it conserved. Considering that the prototype can be used repeatedly in other similar projects, the PIBIMS indeed is useful for enhancing energy efficiency in prefabricated construction.

[Table 1 near here]

\subsection{Enhancing energy efficiency by decreasing human errors}

It has been recognized that the operational errors have been significantly reduced based on the feedback of interviewees. As expressed by the interviewed manager from Company A, the connection between PPP and OAP has avoided the manufacturing of misplaced prefabricated components by enabling timely communication among different parties. The interviewed manager and drivers from Company B also agreed that the synchronization of three platforms has positive impacts on the accuracy of transportation. From their points of view, it was particularly useful for functions of "alarm” when drivers got wrong vehicles.

In a similar vein, workers from Company $\mathrm{C}$ replied that the prototype offered them a valid checking mechanism when searching components and conducting installations. As shown in Table 1, the "accuracy rate of on-site assembly" was increased from the original $99.85 \%$ to $100 \%$. Since a single prefabricated component is large in size and costly in energy, the assembly accuracy is significant in terms of the energy and labour saving. For example, during the pilot period, a total of 1,354 pieces of precast façade have been installed. Provided that the $0.15 \%$ of installation accuracy rate was absent, about 2 pieces of precast façade would have been knocked 
down and re-installed. According to Mao et al. (2013), the embodied energy of one piece of façade that weighs 14 tons is estimated to include 5.83 litres of diesel, 53.52 $\mathrm{kWh}$ of electricity, and $14.87 \mathrm{~m}^{3}$ of water. Therefore, such an increase in installation accuracy conserved quite a substantial amount of energy.

\subsection{Enhancing energy efficiency by supporting the resource management}

The interviewed workers and managers from all three companies agreed that, by taking advantages of the prototype, a considerable amount of time and recourses spent on daily operations were saved. For example, both interviewed managers from Company C confirmed that, facilitated by OAP, they could review the real-time status and location of each prefabricated component, and thereby determine more accurate on-site buffers for heading on towards the JIT philosophy. $75 \%$ of the interviewed workers recognized that the smartphone Apps helped them to finish their work with less time. This can be observed from Table 1 that the time used for recording the installation of a single wing of 23 facades was reduced by 14 minutes than before, and the time spent on finding a target component was decreased from 6-7 minutes to 3-4 minutes.

The interviewed logistics manager noted that scheduling transportation tasks was greatly eased by PTP. He could import the due date of each task into PTP which automatically computed task priorities to support more accurate scheduling (e.g., the average "waiting time for delivery" was decreased from 2 hours to 1.5 hours, see Table 1). The interviewed manager from Company A expressed that, with the advent of the real-time information, he could make production plans much more accurately than before. As presented in Table 1, enabled by the prototype, the average "Working-in-process inventory" was decreased from 110 sets to 98 sets. This shows 
that the prototype is helpful for reducing non-value-adding activities and managing resources more efficiently.

\section{Conclusions}

In light of the importance of energy conservation nowadays, there emerges a global demand of new managerial and technological concepts to avoid wasteful energy consumption. This study has been geared for achieving higher energy efficiency in prefabricated construction by innovatively developing a Physical Internet-enabled Building Information Modelling System (PI-BIMS). The PI-BIMS enables collecting, transmitting, processing, and visualizing the real-time project information across the project processes. Facilitated by the PI-BIMS, it becomes possible for the contractor to allocate labours and machines on-site explicitly; for the logistics company to make more accurate transportation plans; and for the manufacturer to timely adjust production plans subject to order changes. The PI-BIMS developed in the present research is also scalable to other construction projects, particularly for those where prefabrication techniques are used, for addressing the energy consumption issues.

Alongside the manifold advantages of the PI-BIMS, challenges of applying it to real-life projects emerge in terms of technology and people. Regarding technological challenges, the major problem is the stability of networks for communicating the information. If networks were unavailable, workers cannot access to platforms and transmit the real-time information. In this situation, delays will occur for uploading the collected information. Secondly, it was found that about $1.5 \%$ of RFID tags having failed in being responsive after concreting during the pilot period, perhaps due to that the tags were damaged by the force of concrete pouring. More stable networks and RFID tags are needed for solving these technical problems 
Additionally, though it has attached attentions to minimize impacts on workers' daily workflows when devising the PI-BIMS, such impacts cannot be thoroughly avoided due to workers' reluctance of adopting new technologies. It was found workers did not consistently follow the standardized workflow required by the PI-BIMS. Such problem can be partially solved by labour training and demonstrating the benefits of the system to managers and workers (Dai et al. 2012). Future studies of this research thus could be heading on towards meeting challenges, sourced from both technical and managerial aspects, to enhance energy efficiency in prefabricated construction.

\section{Acknowledgement}

This work is supported by the Innovation and Technology Fund of the Hong Kong Innovation and Technology Commission (ITC) under Grant ITP/045/13LP. The authors are grateful to the Hong Kong Housing Authority, Gammon Construction Limited, Wing Hong Shun Enterprise Limited, and Yingyun Transportation Limited.

\section{References}

Azhar, S., W. A. Carlton, D. Olsen, and I. Ahmad. 2011. "Building information modeling for sustainable design and LEED ${ }^{\circledR}$ rating analysis.” Automation in Construction 20 (2): 217-224. doi: 10.1016/j.autcon.2010.09.019.

Babič, N. Č., P. Podbreznik, and D. Rebolj. 2010. “Integrating resource production and construction using BIM.” Automation in Construction 19 (5), 539-543. doi: 10.1016/j.autcon.2009.11.005.

Bazjanac, V. 2004. "Building energy performance simulation as part of interoperable software environments”. Building and Environment 39 (8): 879-883. doi: 10.1016/j.buildenv.2004.01.012.

Benjaoran, V., and N. Dawood. 2006. “Intelligent approach to production planning system for bespoke precast concrete products.” Automation in Construction 15 (6): 737-745. doi: 10.1016/j.autcon.2005.09.007.

Bynum, P., R.R. Issa, and S. Olbina. 2012. "Building information modeling in support of sustainable design and construction.” Journal of Construction Engineering 
and Management 139 (1): 24-34. doi: 10.1061/(ASCE)CO.1943-7862.0000560.

Chen, K., W. Lu, Y. Peng, S. Rowlinson, and G. Q. Huang. 2015. “Bridging BIM and building: From a literature review to an integrated conceptual framework.” International Journal of Project Management 33 (6): 1405-1416. doi: 10.1016/j.ijproman.2015.03.006.

Chuang, T. H., B. C. Lee, and I. C., Wu. 2011. "Applying cloud computing technology to BIM visualization and manipulation.” Paper presented at the 28th International Symposium on Automation \& Robotics in Construction, Seoul, Korea, June 29-July 2.

Crowther, P. 1999. "Design for disassembly to recover embodied energy.” Paper presented at the 16th Annual Conference on Passive and Low Energy Architecture, Melbourne, Australia, September.

Dai, Q. Y., R. Y. Zhong, G. Q. Huang, T. Qu, T. Zhang and T. Y. Luo. 2012. "Radio frequency identification-enabled real-time manufacturing execution system: a case study in an automotive part manufacturer." International Journal of Computer Integrated Manufacturing 25 (1): 51-65. doi: 10.1080/0951192X.2011.562546.

Dixit, M. K., J. L. Fernández-Solís, S. Lavy, and C. H. Culp. 2010. “Identification of parameters for embodied energy measurement: A literature review.” Energy and Buildings 42 (8): 1238-1247. doi: 10.1016/j.enbuild.2010.02.016.

Eichholtz, P., N. Kok, and J. M. Quigley. 2010. “Doing well by doing good? Green office buildings.” The American Economic Review 100 (5): 2492-2509. doi: 10.1257/aer.100.5.2492.

Gibb, A.G. 1999. Off-site fabrication: prefabrication, pre-assembly and modularisation. John Wiley \& Sons.

Gubbi, J., R. Buyya, S. Marusic, and M. Palaniswami. 2013. "Internet of Things (IoT): A vision, architectural elements, and future directions.” Future Generation Computer Systems 29 (7): 1645-1660. doi: 10.1016/j.future.2013.01.010.

Heydarian, A., and M. Golparvar-Fard. 2011. "A visual monitoring framework for integrated productivity and carbon footprint control of construction operations.” In Proceedings of the 2011 ASCE International Workshop on Computing in Civil Engineering, edited by Yimin Zhu and R. Raymond Issa, 504-511. American Society of Civil Engineers. doi: 10.1061/9780784411827.

Hong, J. K., G. Q. Shen, C. Mao, Z. D. Li, and K. J. Li. 2016. “Life-cycle energy 
analysis of prefabricated building components: an input-output-based hybrid model." Journal of Cleaner Production 112: 2198-2207. doi: 10.1016/j.jclepro.2015.10.030.

$\mathrm{Hu}$, W. 2005. “Automatic construction process of prefabricated buildings on geometric reasoning." In Proceedings of the Construction Research Congress 2005, edited by Iris D. Tommelein, 1-10. American Society of Civil Engineers. doi: 10.1061/40754(183)11.

Irizarry, J., E. P. Karan, and F. Jalaei. 2013. "Integrating BIM and GIS to improve the visual monitoring of construction supply chain management.” Automation in Construction 31: 241-254. doi: 10.1016/j.autcon.2012.12.005.

Jeong, W., S. Chang, J. Son, and J. S. Yi. 2016. "BIM-Integrated construction operation simulation for just-in-time production management.” Sustainability 8 (11): 1106. doi: 10.3390/su8111106.

Krygiel, E., and B. Nies. 2008. Green BIM: successful sustainable design with building information modeling. John Wiley \& Sons.

Laine, T., A. Karola, and O.G. Oy. 2007. "Benefits of building information models in energy analysis”. In Proceedings of the Clima 2007 WellBeing Indoors. Finnish Association of HVAC Societies, Helsinki, Finland.

Li, H., H. L. Guo, M. Skitmore, T. Huang, K. Y. N. Chan, and G. Chan. 2011. "Rethinking prefabricated construction management using the VP model in Hong Kong.” Construction Management and Economics 29 (3): 233245. doi: 10.1080/01446193.2010.545994.

Lu, W. S., and H. P. Yuan. 2013. "Investigating waste reduction potential in the upstream processes of offshore prefabrication construction.” Renewable and Sustainable Energy Reviews 28: 804-811. doi: 10.1016/j.rser.2013.08.048.

Mao, C., Q. Shen, L. Shen, and L. Tang. 2013. “Comparative study of greenhouse gas emissions between off-site prefabrication and conventional construction methods: two case studies of residential projects.” Energy and Buildings 66: 165-176. doi: 10.1016/j.enbuild.2013.07.033.

Montreuil, B. 2011. “Toward a Physical Internet: meeting the global logistics sustainability grand challenge”. Logistics Research 3 (2): 71-87. doi: 10.1007/s12159-011-0045-X.

Montreuil, B., R. D. Meller, and E. Ballot. 2013. "Physical internet foundations.” In Service Orientation in Holonic and Multi Agent Manufacturing and Robotics, 
edited by Theodor Borangiu, Andre Thomas, and Damien Trentesaux, 151-166. Springer Berlin Heidelberg.

NIBS (National Institute of Building Science) 2015. "National BIM Standard-United States V3”. Accessed 20 May 2016. https://www.nationalbimstandard.org/.

Neelamkavil, J. 2009. “Automation in the prefab and modular construction industry.” Paper presented at the 26th International Symposium on Automation \& Robotics in Construction, Austin, U.S., June 24-27.

Niu, Y., W. Lu, K. Chen, G. G. Huang, and C. Anumba. 2015. "Smart Construction Objects.” Journal of Computing in Civil Engineering, 04015070. doi: 10.1061/(ASCE)CP.1943-5487.0000550.

Pheng, L. S., and C. J. Chuan. 2001. "Just-in-time management of precast concrete components.” Journal of Construction Engineering and Management 127 (6): 494-501. doi: 10.1061/(ASCE)0733-9364(2001)127:6(494).

Qiu, X., H. Luo, G. Y. Xu, R. Y. Zhong, and G. Q. Huang. 2015. "Physical assets and service sharing for IoT-enabled Supply Hub in Industrial Park (SHIP).” International Journal of Production Economics 159: 4-15. doi: 10.1016/j.ijpe.2014.09.001.

Reddy, B. V., and K. S. Jagadish. 2003. "Embodied energy of common and alternative building materials and technologies.” Energy and Buildings 35 (2): 129-137. doi: 10.1016/S0378-7788(01)00141-4.

Stadel, A., J. Eboli, A. Ryberg, J. Mitchell, and S. Spatari. 2011. "Intelligent sustainable design: Integration of carbon accounting and building information modeling." Journal of Professional Issues in Engineering Education and Practice 137 (2): 51-54. doi: 10.1061/(ASCE)EI.1943-5541.0000053

Treloar, G. J., P. E. Love, and G. D. Holt. 2001. “Using national input/output data for embodied energy analysis of individual residential buildings.” Construction Management and Economics 19 (1): 49-61. doi: 10.1080/014461901452076.

Yee, A. A. 2001. "Structural and economic benefits of precast/prestressed concrete construction." PCI Journal 7 (8): 34-42. url: http://www.precastdesign.com/media/publications/2001_0701_Structural_and_ Economic_Benefits.pdf

Zhang, Y. F., G. Zhang, J. Q. Wang, S. D. Sun, S. B. Si, and T. Yang. 2015. "Realtime information capturing and integration framework of the internet of manufacturing things." International Journal of Computer Integrated 
Manufacturing 28 (8): 811-822. doi: 10.1080/0951192X.2014.900874.

Zhong, R. Y., Q. Dai, T. Qu, G. Hu, and G. Q. Huang 2013a. "RFID-enabled realtime manufacturing execution system for mass-customization production.” Robotics and Computer Integrated Manufacturing 29 (2): 283-292. doi: 10.1016/j.rcim.2012.08.001.

Zhong, R. Y., Z. Li, L. Y. Pang, Y. Pan, T. Qu, and G. Q. Huang. 2013b. "RFIDenabled real-time advanced planning and scheduling shell for production decision making." International Journal of Computer Integrated Manufacturing 26 (7): 649-662. doi: 10.1080/0951192X.2012.749532.

Zhong, R. Y., Y. Peng, F. Xue, J. Fang, W. Zou, H. Luo, S. T. Ng, W. Lu, G. Q. Shen, and G. Q. Huang 2017. "Prefabricated construction enabled by the Internet-ofThings.” Automation in Construction 76: 59-70. doi: 10.1016/j.autcon.2017.01.006. 


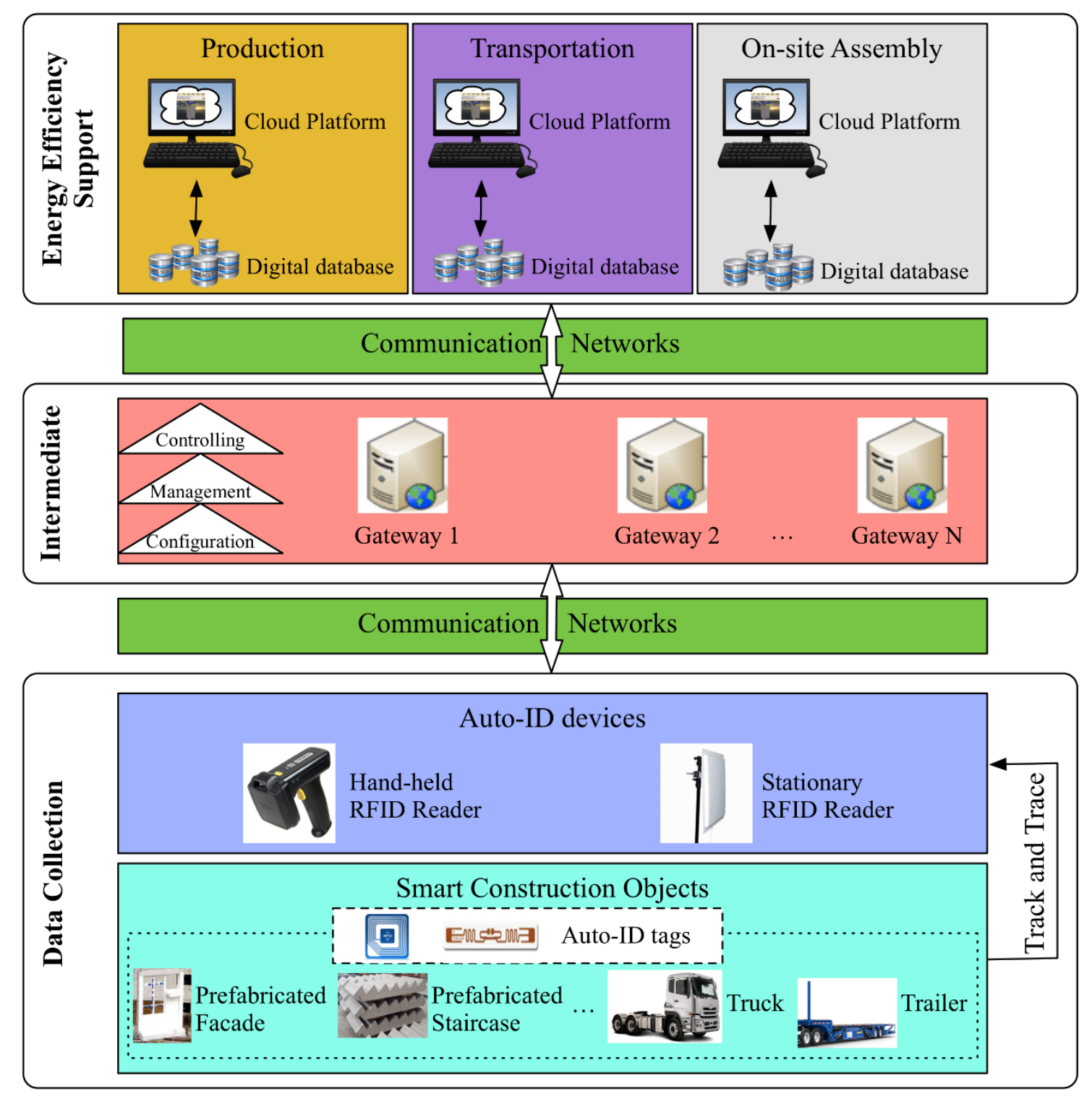

Figure 1. System architecture of PI-BIMS 


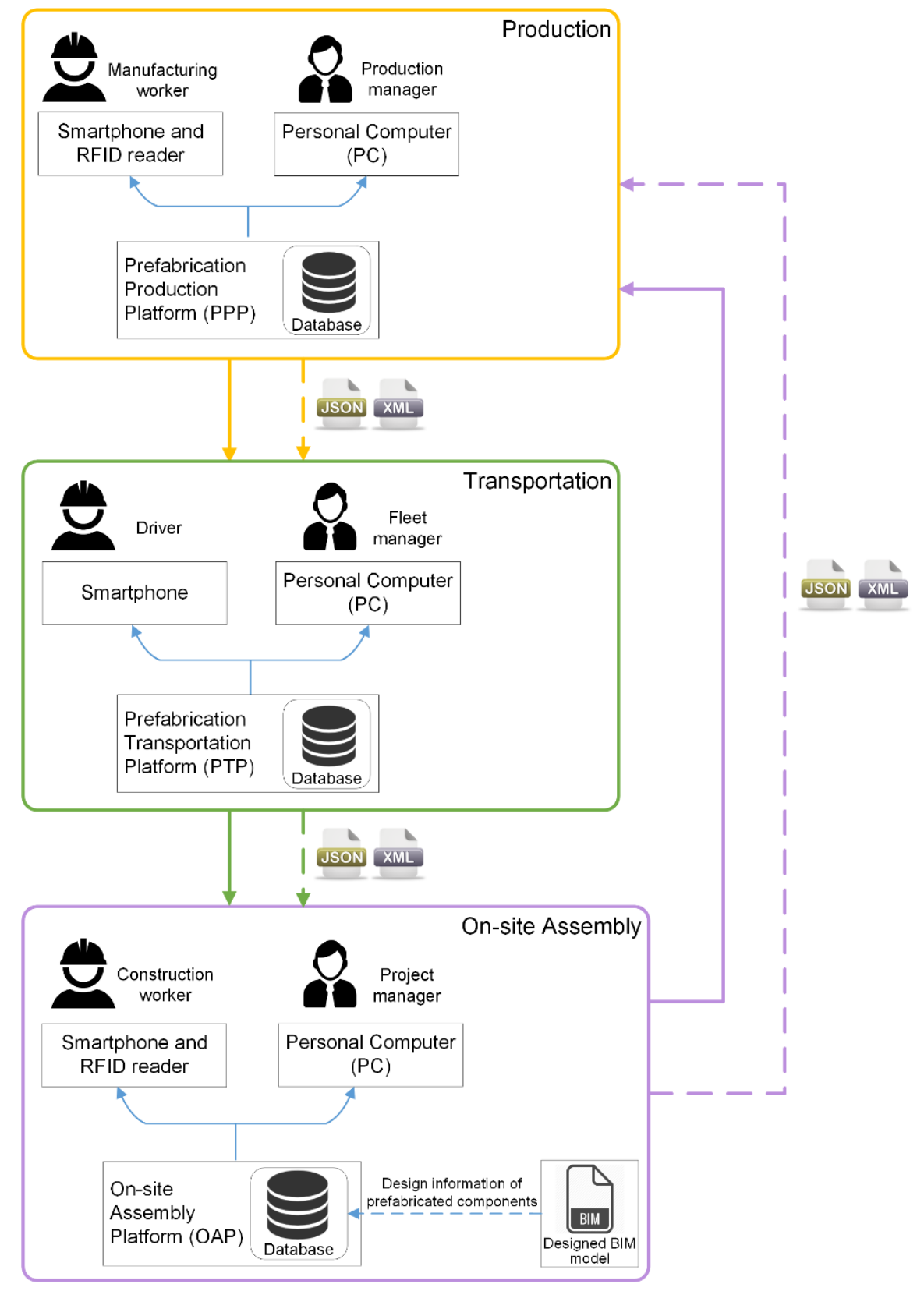

Figure 2. An illustration of the overall workflow 

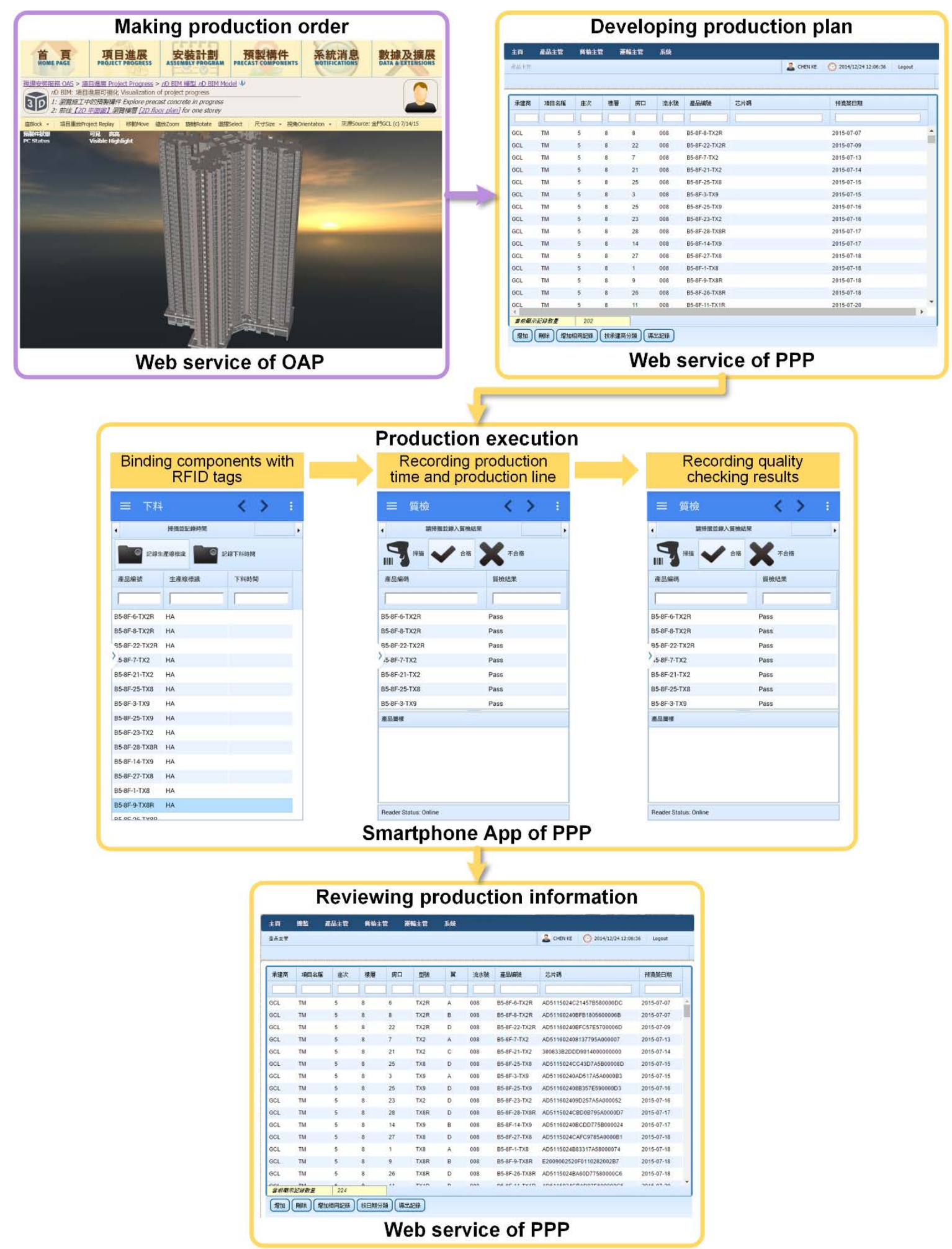

Figure 3. The new workflow of prefabrication production 


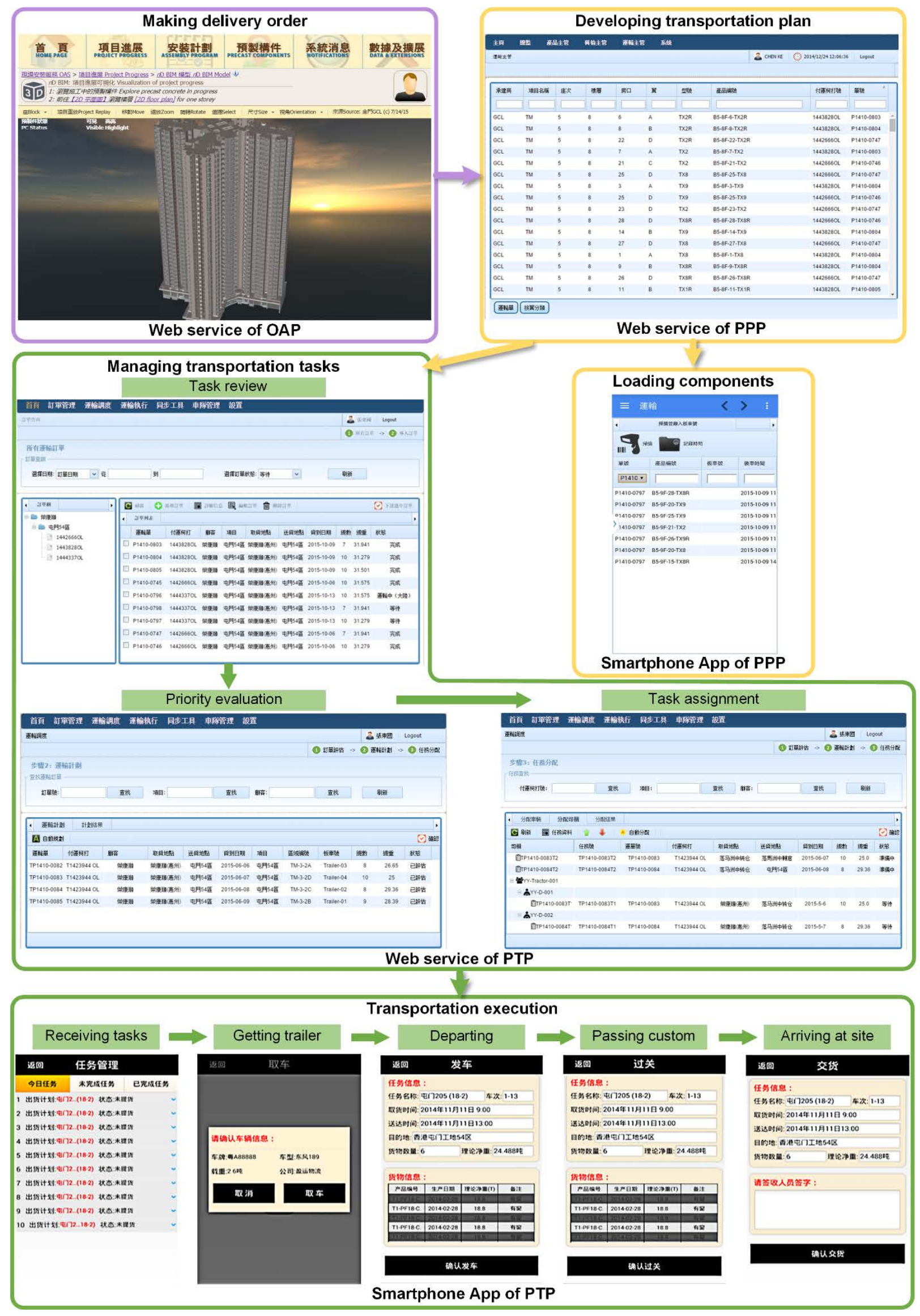

Figure 4. The new workflow of prefabrication transportation 


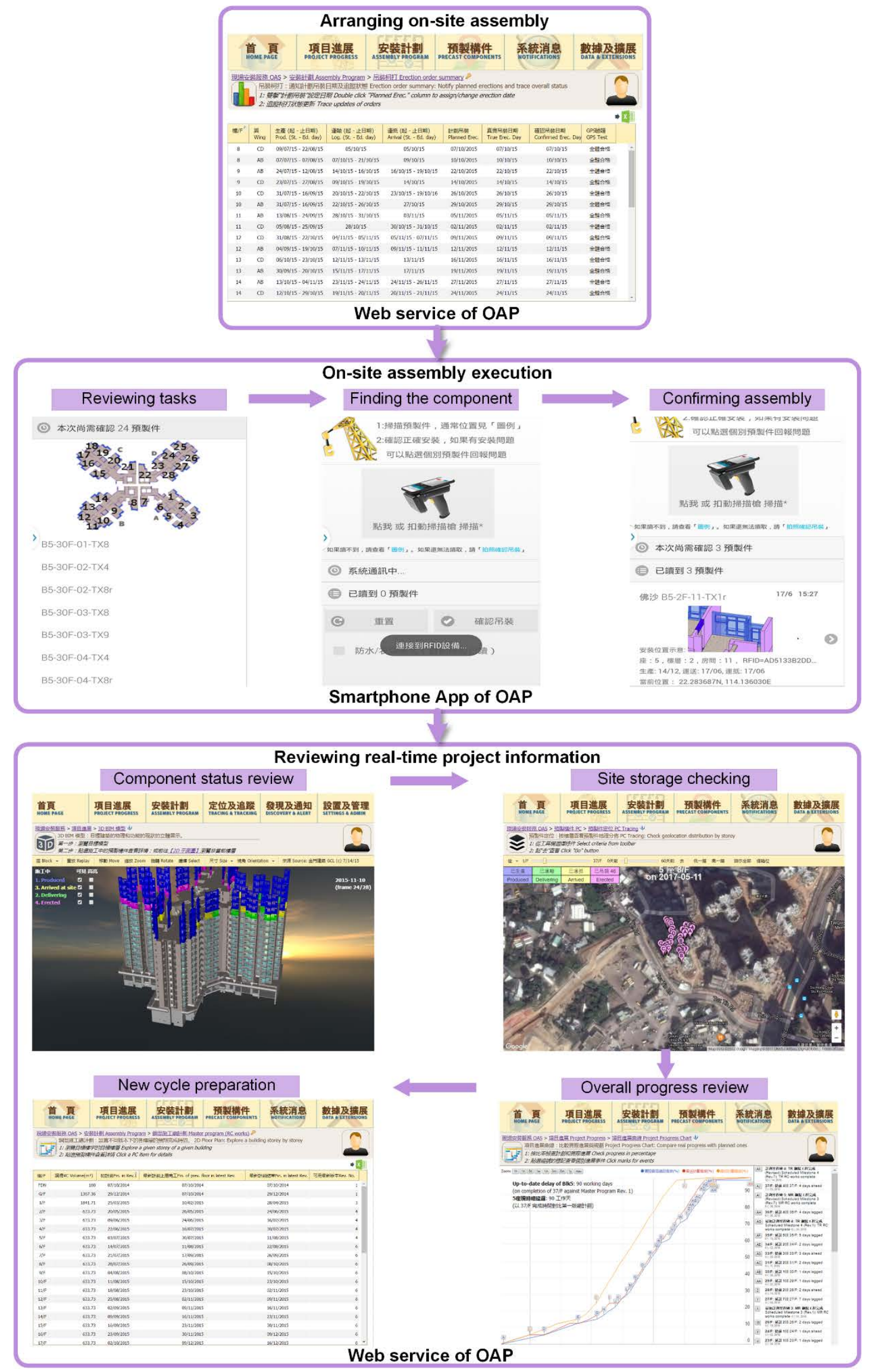

Figure 5. The new workflow of on-site assembly 
Table 1. Causal elements of enhanced energy efficiency

\begin{tabular}{|c|c|c|c|}
\hline Company & $\begin{array}{l}\text { Causal Elements (Average } \\
\text { Value) }\end{array}$ & $\begin{array}{l}\text { Previous } \\
\text { Performances }\end{array}$ & $\begin{array}{l}\text { Enhanced } \\
\text { Performances }\end{array}$ \\
\hline \multirow{4}{*}{$\begin{array}{l}\text { Company A } \\
\text { (Production) }\end{array}$} & Production cycle & 10 days & 6 days \\
\hline & $\begin{array}{l}\text { Working-in-Process (WIP) } \\
\text { inventory }\end{array}$ & 110 sets & 98 sets \\
\hline & $\begin{array}{l}\text { Time length for locating a } \\
\text { component }\end{array}$ & 7-8 minutes & 5-6 minutes \\
\hline & Paper work & $\begin{array}{l}\text { 200-300 sheets of } \\
\text { A4-sized paper } \\
\text { per day }\end{array}$ & $\begin{array}{l}\text { 110-140 sheets } \\
\text { of A4-sized } \\
\text { paper per day }\end{array}$ \\
\hline \multirow{3}{*}{$\begin{array}{l}\text { Company B } \\
\text { (Transportation) }\end{array}$} & Paper work & $\begin{array}{l}5 \text { sheets of A4- } \\
\text { sized paper per } \\
\text { car }\end{array}$ & $\begin{array}{l}3 \text { sheets of A4- } \\
\text { sized paper per } \\
\text { car }\end{array}$ \\
\hline & Waiting time for delivery & 2 hours & 1.5 hours \\
\hline & Time used for order picking & 2 hours per car & 1.2 hours per car \\
\hline \multirow{3}{*}{$\begin{array}{l}\text { Company C } \\
\text { (On-site assembly) }\end{array}$} & $\begin{array}{l}\text { Time length for locating a } \\
\text { component }\end{array}$ & 6-7 minutes & 3-4 minutes \\
\hline & $\begin{array}{l}\text { Accuracy rate of on-site } \\
\text { assembly }\end{array}$ & $99.85 \%$ & $100 \%$ \\
\hline & $\begin{array}{l}\text { Time used for recording the } \\
\text { installation of a wing }\end{array}$ & 30 minutes & 16 minutes \\
\hline
\end{tabular}

